\title{
PATRIMÔNIO CULTURAL E MEMÓRIA LITERÁRIA: MEMÓRIAS URBANAS NA LITERATURA BAIANA CONTEMPORÂNEA
}

\author{
Milena Guimarães Andrade Tanure \\ Doutoranda em Literatura e Cultura (Ppglitcult/UFBA) \\ milenatanure@gmail.com
}

\section{RESUMO}

Os espaços urbanos apresentam-se como patrimônio constitutivo da identidade e memória da cidade e de seus cidadãos e devem ser protegidos pela sua natureza significativa. O presente artigo tem como objeto a produção literária do escritor contemporâneo Carlos Ribeiro e desenvolve-se a fim de analisar como, a partir de representações do espaço urbano, o texto literário desse escritor baiano é capaz de engendrar a leitura de memórias subjetivas e coletivas, resguardando, portanto, pela via literária, patrimônios culturais de suma relevância social.

Palavras-chave: espaço urbano, memória, representação, Carlos Ribeiro.

\begin{abstract}
Urban spaces present themselves as a patrimony constitutive of the identity and memory of the city and of its citizens and they should be protected due to their significant nature. This paper aims at the literary production of the contemporary writer Carlos Ribeiro, in order to analyze how, from representations of urban space, the literary text of this writer from Bahia is capable of engendering the reading of subjective and collective memories, protecting, therefore, by means of literature, cultural patrimony of great social relevance.
\end{abstract}

Keywords: urban space, memory, representation, Carlos Ribeiro.

No final do século XVIII, o Estado moderno, em nome do interesse público, assumiu a proteção legal de bens determinados, aos quais foi atribuída a capacidade de simbolizar a nação. Foi nesse momento que surgiu a noção de patrimônio histórico e artístico da nação. Há que se perceber, contudo, que, no Brasil, a temática do patrimônio - entendida como preocupação em salvaguardar os vestígios da memória nacional e os objetos de valor histórico e artístico - só passou a ser considerada relevante e a contar com a intervenção 
estatal a partir dos anos de 1920. Embora já estivessem funcionando os grandes museus nacionais, não existiam os meios para proteger os bens que não integravam tais coleções, como os bens imóveis. Ademais, com as denúncias de intelectuais contra o abandono das cidades históricas, o tema passou a ser debatido nas instituições culturais, no Congresso Nacional, nos governos estaduais e na imprensa (FONSECA, 2005).

Maria Cecília Londres Fonseca (2005) indica que é uma característica específica dos Estados modernos a constituição de patrimônios históricos e artísticos nacionais por meio de intelectuais recrutados e institutos jurídicos próprios. Tais bens, tidos como patrimônios, passam a ser merecedores de proteção para as gerações futuras em razão do valor que lhes é atribuído como manifestação cultual e símbolo da nação. Salienta, assim, que o discurso que é utilizado para justificar a constituição do patrimônio histórico e artístico nacional e o desenvolvimento das políticas de preservação se desenvolve no sentido de reforçar uma identidade coletiva e promover a educação e formação de cidadãos. Dessa forma, as políticas de preservação se propõem a atuar, basilarmente, no nível do simbólico.

Traçando esse panorama histórico, Maria Cecília Fonseca (2005) apresenta que, a partir da concepção que tinham sobre arte, história, tradição e nação, foram alguns intelectuais modernistas que elaboraram essa ideia na forma do conceito de patrimônio que, em nosso país, tornou-se hegemônico e foi adotado pelo Estado por meio do Serviço do Patrimônio Histórico e Artístico Nacional (Sphan), atual Instituto do Patrimônio Artístico Nacional (IPHAN). Tais intelectuais, em sua maioria do campo literário, foram responsáveis por, a partir de 1936, com a criação do Sphan, implantar um serviço que se destinava à proteção de obras de arte e história no país. Fonseca (2005) oferta especial destaque à 
atuação dos artistas modernistas em assegurar um movimento cultural renovador em uma época de governo autoritário, a instauração do Estado Novo. Há que se observar, ainda, o destaque ofertado ao caráter heterogêneo e amplo de tal movimento, uma vez que suas propostas extravasaram o âmbito artístico.

Nesse apanhado histórico, observa-se que a atuação dos literatos modernistas deu-se, antes mesmo da semana de 1922, a partir da publicação de artigos denunciando a ameaça de irrecuperável perda das artes coloniais. As primeiras manifestações do poder público às insatisfações de tais intelectuais partiram dos governos estaduais pela criação de Inspetorias Estaduais de Monumentos Históricos. No âmbito federal, por sua vez, houve a elaboração de um projeto de lei em nome da defesa de tal patrimônio, tido, no entanto, como inviável, uma vez que relacionava proteção e desapropriação. Muitas outras propostas legislativas foram barradas no Congresso, sobretudo por esbarrar no direito garantido constitucionalmente à propriedade. Com o Estado Novo, no entanto, tem-se a adoção do ideário de patrimônio pelo projeto da construção de uma nação pelo Estado (FONSECA, 2005).

Nesse cenário, Fonseca (2005) destaca a atuação do Ministro Capanema ${ }^{1}$ no intuito de assegurar a proteção dos monumentos e obras de arte nacionais a partir da criação de um órgão destinado especificamente para isso (Sphan). Todo o projeto de preservação patrimonial do Ministro originou-se com o anteprojeto do poeta modernista Mario de

\footnotetext{
${ }^{1}$ Gustavo Capanema Filho (1900-1985), além de Ministro da Educação e Saúde na Era Vargas durante o período de 1934 a 1945, foi um político e intelectual que atuou com grande interesse artístico e modernista sobre a política cultural do país. No intuito de associar o desenvolvimento do país e as políticas públicas voltadas à promoção da cultura nacional, Capanema atuou ativamente na promoção e preservação de uma cultura nacional, tendo sido responsável pela criação do Serviço de Patrimônio Histórico e Artístico Nacional (Sphan).
} 
Andrade e com a posterior formulação do decreto-lei no 25 de 1937, substancialmente, por Rodrigo M. F. de Andrade, presidente, por longo período, do Sphan.

O que se vai delineando a partir desse apanhado histórico sobre o patrimônio cultural brasileiro dá indícios da latente participação do universo literário nas primeiras manifestações públicas em defesa de uma memória nacional. Nesse sentido, cabe destacar a atuação de Mário de Andrade e suas investidas quase etnográficas no intuito de mapear e valorizar o patrimônio artístico e cultural do país. Além disso, em muitas das apreciações dos processos de tombamento daquele período, escritores de grande projeção foram chamados para avaliar a relevância de determinados patrimônios, como Drummond ${ }^{2}$.

Para além dessa atuação política e administrativa dos escritores, não há como se alhear ao fato de a literatura nacional, constituindo-se, também ela, como patrimônio do país, evocar em muitas de suas narrativas imagens de patrimônios culturais. Por vezes, a presença de tais patrimônios não se faz de modo gratuito, mas no escopo de uma discursividade política de valorização e proteção da memória de um povo. Nesse cenário, encontra-se a produção literária do professor, jornalista e escritor baiano Carlos Ribeiro. 0 presente artigo, a partir de tais provocações, desenvolve-se no intuito de avaliar a representação de uma cidade de Salvador em sua narrativa, marcada por um tom memorialístico que diz respeito não apenas às memórias individuais das personagens, do escritor ou de um provável leitor das narrativas, mas também às memórias coletivas que se desvendam a partir da representação do espaço urbano. Na obra de Carlos Ribeiro é possível identificar uma escrita de si que, pela representação da cidade - lugar de diversas vivências

\footnotetext{
${ }^{2}$ Carlos Drummond de Andrade (1902-1987), além de grande poeta da segunda geração modernista, atuou ativamente da gestão Capanema, tendo sido seu Chefe de Gabinete e o assessorado em suas funções como Ministro.
} 
-, também constitui uma escrita de memórias coletivas. Os seus contos e romances colocam em cena becos, casarões e ruas que apresentam uma simbologia diretamente associada às vivências experimentadas ao longo do curso da história urbana e da vida dos seus cidadãos. É válido destacar, assim, que os espaços ganham a sua natureza significativa a partir das situações que são nele vividas e, por essa razão, passam a ser protegidos como os patrimônios culturais que são, quer pelos institutos jurídicos que o buscam resguardar, quer pela própria literatura e suas representações.

\section{O PATRIMÔNIO CULTURAL E UM DIREITO À MEMÓRIA DO ESPAÇO URBANO PELA VIA LITERÁRIA}

Pensando-se a relação entre as subjetividades, cidade e a necessidade de se preservarem locais identitários, percebe-se como a força significativa de um espaço urbano em muito se relaciona com as vivências e experiências experimentadas nesse espaço. Assim, com afirma Duarte:

A construção dos lugares é rica pois não diz respeito às pedras, mas às suas escolhas, sua organização, sua finalidade e sobre o amálgama etéreo que as une. Assim como a casa pode ser vista como síntese do processo de construção de um lugar e sua similaridade com a construção psicológica de seu construtor, a apropriação de espaços urbanos, potencialmente constituídos por um número maior de elementos, e, principalmente vivido coletivamente, faz-se pela vivência de seus lugares, que são construídos pelo uso. (DUARTE, 2002, p. 75).

Desse modo, é pelo uso que o centro da cidade, por exemplo, é significado e passa a entrelaçar memórias subjetivas e coletivas. Os elementos que compõem tal espaço, para além de darem forma à cidade, constituem os elementos identitários que interligam sujeitos e gerações. Dessa forma, a memória de cada um dos seus moradores se estrutura tendo 
como espaço das narrativas de si a cidade que ele ajuda a moldar pelo seu uso. Nesse mesmo sentido, por serem vividas, em sua maioria, na coletividade, as relações entre sujeitos e espaços compõem memórias que ultrapassam a esfera subjetiva e passam a dizer respeito a uma coletividade que se identifica, em especial, pelo espaço em que se desenrolam suas vidas.

Fazendo uma leitura da obra A memória Coletiva, de Habawachs, Giovanaz (2007) evidencia o modo como esse autor coloca em cena que a manutenção da memória coletiva dos cidadãos requer uma preservação dos espaços, uma vez que

[...] a permanência e a estabilidade dos objetos materiais que nos cercam e com os quais estamos em contato diário nos propicia um equilíbrio mental, como se fosse uma sociedade silenciosa e imóvel, estranha às nossas transições e mudanças, proporcionando-nos uma sensação de ordem e de continuidade. O nosso entorno material conserva nossas marcas e a de nossos mais queridos, lembram-nos fatos importantes de nossa vida individual e estão associados à memória de nosso grupo. Todo espaço habitado recebe as marcas dos indivíduos que nele transitam. Os quarteirões no interior da cidade, bem como as casas que os constituem, estão também ligados ao solo, como as árvores, os rochedos e as montanhas. (GIOVANAZ, 2007, p. 237).

Nesse sentido, subjaz a tais afirmações o fato de que ao indivíduo interessa a manutenção dos espaços públicos constitutivos das memórias, uma vez que, constituindo-se a memória, constitui-se a si. Assim, a preservação do espaço urbano constitui a manutenção, também, das memórias subjetivas. É por isso que "destruída a parte de um bairro onde se prendiam lembranças da infância do seu morador, algo de si morre junto com as paredes ruídas, os jardins cimentados" (BOSI, 1979, p. 370). Como afirma Habawachs (1990), sendo eliminada ou modificada a forma ou orientação das casas ou ruas, os materiais e pedras não irão apresentar resistência. No entanto, os grupos resistirão “com a própria resistência, 
senão das pedras, pelo menos de seus antigos arranjos na qual vos esbarreis", uma vez que dela veio a força da tradição local.

Pensando esse tipo de resistência, a crítica literária tem demarcado nas escritas atuais a presença constante de um homem contemporâneo que, atravessado pelas transformações do seu tempo, é representado, ou se faz representar, por meio de uma escrita memorialística questionadora e, em sua subjetividade, amplamente universal. A prosa ficcional do escritor baiano Carlos Ribeiro tem se inserido expressivamente nesse cenário, uma vez que temos, em sua maioria, histórias que, no tratamento de temas individuais, abarcam questões coletivas. Nesse sentido, podemos perceber que, se em alguns momentos a escrita de Ribeiro aparenta ser intimista, sobretudo nas narrativas em primeira pessoa, assim não se apresenta ao se avaliar o seu conteúdo, uma vez que o "eu" que se enuncia evoca memórias plurais de diferentes sujeitos e gerações.

Esse homem, envolvido pelas questões inerentes ao seu tempo, revela, pela literatura, as angústias e incertezas em que está submergido. Nesse cenário, o texto literário tem sido utilizado para tentar recuperar o que foi perdido e que teria o poder de conferir o reconhecimento e o sentimento de estabilidade e pertencimento. Percebe-se, assim, que, “com a pós-modernidade, que representa o fim daquilo que Jean-François Lyotard chamou de grandes narrativas [...] o futuro desaparece do campo de visão. Atolado no presente, o sujeito vai-se projetar sobre o passado, o que explica a proliferação das escritas da memória e da história" (FIGUEIREDO, 2013, p. 25). Ao tratar do crescimento dessas práticas de rememoração e a proliferação de literatura memorialística, biografias, autobiografias ou autoficção, Eurídice Figueiredo (2013, p. 25, grifo da autora) afirma que "o sujeito tem 
necessidade de dizer eu para sair da indistinção pós-moderna, ele precisa prover o eu de marcas distintivas que possam confirmar sua existência, assinalar seu pensamento e reforçar sua singularidade".

Pierre Nora (2009, p. 6) afirma que o mundo está experimentando a emergência da memória, "[...] é como uma onda de recordação que se espalhou através do mundo e que, em toda parte, liga firmemente a lealdade ao passado - real ou imaginário - e a sensação de pertencimento, consciência coletiva e autoconsciência".

A partir da compreensão aqui apresentada, de que vivemos o "tempo da memória" (NORA, 2009, p. 7), percebe-se que "não há dúvida de que o mundo está sendo musealizado e que todos nós representamos os nossos papéis neste processo. É como se o objetivo fosse conseguir a recordação total" (HUYSSEN, 2000, p. 15). Carlos Ribeiro, a partir da sua produção literária, aparenta tomar para si o papel de, pela representação do que não mais existe, trazer para o presente aquilo que fincou suas raízes no passado e que constitui lembranças importantes demais para serem obliteradas. Nas narrativas de Ribeiro, um eu que se coloca na narrativa, por meio dos narradores ou personagens, distingue-se da multidão ao, perambulando pela cidade, retomar antigas vivências, experiências e locais que fincaram raízes na memória. A retomada do passado se apresenta, assim, como tentativa de se resguardar aquilo que vai se apagando na imagem atual do espaço urbano, mas que é nítido e significativo para aquele que rememora. Nesse contexto, cabe destacar, em especial, como a representação do antigo espaço central da cidade de Salvador, hoje denominado Centro Histórico ou Antigo, a depender da região abarcada, faz-se presente nas narrativas de Ribeiro. 


\section{O CENTRO HISTÓRICO E UMA IMAGEM DE BAHIA: O PELOURINHO}

No início da década de 1960, Carlos Ribeiro viveu no hoje denominado centro antigo, tendo morado no Pelourinho. Diante de seu contato com essa antiga centralidade e sua atuação jornalística e literária pela preservação dos espaços naturais e culturalmente relevantes, Ribeiro aparenta ter tomado para si o dever de resguardar este centro em sua antiga conformação, assim como as práticas sociais que se fizeram marcantes. Dessa forma, as representações desse espaço revelam vivências inesquecíveis, sobretudo da infância, que são indispensáveis para se construir simbolicamente os espaços urbanos.

Nesse momento, analisaremos o Centro Histórico apresentado nas narrativas de Carlos Ribeiro. A princípio, é válido sinalizar que, em suas representações da antiga centralidade, Ribeiro lança um olhar sobre esse espaço da cidade marcado pelo tom nostálgico. No conto “O visitante invisível”, primeiro de Contos de Sexta-feira (2010), é perceptível que a visão do eu é formada por uma emotividade que tenta, pela memória, recuperar as vivências da infância e uma reaproximação espaço-temporal com aquilo que foi significante. Nessa narrativa, a voz que se enuncia convida o leitor a, percorrendo o Pelourinho do passado, visitar antigos espaços e, silenciosamente, assistir a vivência de uma família, sobretudo de um menino que brinca em um antigo quarto, e que remete à própria experiência narrada por Ribeiro em algumas de suas entrevistas e comunicações.

Nas primeiras passagens do conto, um eu ficcional marcado pelo sentimento de nostalgia tenta reconstituir as vivências deixadas para trás pelas mudanças da vida e os lugares afetivos corroídos pelas transformações da cidade. No início da narrativa, 
apresenta-se para o leitor o espaço a ser desvelado pelo retorno ao passado, o centro antigo da cidade do Salvador:

Escuta. Façamos de conta que você possa tornar-se invisível. E que possa fazer uma viagem no tempo. Você desce, agora a ladeira do Pelourinho, vê? É um dia qualquer de 1963. O céu tem uma intensa luminosidade avermelhada. Uma menina, com um vestido amarelo, toca acordeom na janela de um sobrado. Um bêbado dorme na calçada próxima à Igreja de Nossa Senhora do Rosário dos Pretos. Os casarões são velhos e desbotados. Homens vestem roupas brancas. Sinos tocam nos ares finos da velha Salvador. Você passa pela banca de revistas. Desce a Rua Silva Jardim, no Taboão. Chega em frente ao Plano Inclinado do Pilar. Um homem, com grande bigode grisalho, bebe grapetti com o filho no bar que fica no andar térreo do edifício Bola Verde. Ele compra doces e chocolates. É sábado e ninguém, senão você, carrega um passado que ainda não existe. [...] Talvez por isso quase se possam ouvir sussurros nas varandas e nas sacadas dos casarios. (RIBEIRO, 2010, p. 21).

Em “O visitante invisível”, é possível aferir um tom de angústia e um retorno cíclico ao espaço em que se viveu expressivas experiências. Isso é identificável, por exemplo, a partir da presença do mesmo trecho no início e no final da narrativa: "Escuta. Façamos de conta que você possa tornar-se invisível. E que possa fazer uma viagem no tempo. Você desce, agora, a ladeira do Pelourinho, vê? É um dia qualquer de 1963" (RIBEIRO, 2010, p. 21). A repetição sugere a angústia por aquilo que se perdeu e nos remete a um eterno retorno aos espaços que já não mais são como no passado. Ainda que desintegrados os espaços, a criação dessas memórias se revela uma via de manutenção daquilo que fincou raízes no imaginário do narrador.

No conto, o visitante que narra e o menino que é observado se entrelaçam como se um tivesse criado o outro, e temporalidades distintas se cruzam fantasiosamente. Nesse sentido, é como se o narrador visse a si em um tempo passado. Elaborando o conceito de 
lembrança encobridora, Freud (1899) evidencia que, na maioria das lembranças importantes, aquele que rememora, na recordação, vê-se como criança e está consciente de que tal criança é ele mesmo. Apesar de tal consciência, contudo, aquele que lembra "vê essa criança tal como a veria um observador externo à cena" (FREUD, 1899, p. 189). Na narrativa, isso se faz emblemático, uma vez que aquele que rememora vivências da infância convida o leitor para, silenciosamente e fazendo de conta que é invisível, adentrar os caminhos da memória e ver a si, em uma residência familiar, em um ano específico, 1963.

O narrador que conduz a retomada memorialística olha para si, de fora da vivência rememorada, e se vê criança a brincar em sua casa em meio aos elementos físicos que, reconstituindo um espaço significativo da infância, compõe a lembrança que é construída. Nesse ponto, é válido observar que "sempre que numa lembrança o próprio sujeito assim aparecer como um objeto entre outros objetos, esse contraste entre o ego que age e o ego que recorda pode ser retomado como uma prova de que a impressão original foi elaborada" (FREUD, 1899, p. 189). Como assevera Freud (1899, p. 189), a reconstrução de uma lembrança da infância evidencia o caráter criativo da memória, uma vez que tal cena "não pode ser uma repetição exata da impressão originalmente recebida, pois, na época, o sujeito estava em meio à situação e não prestava atenção a si mesmo, mas sim ao mundo externo".

A voz que se enuncia no conto convida a um passeio por vivências e espaços do passado. Já nas primeiras linhas, a narrativa indica o centro histórico de Salvador como o ambiente a partir do qual são desvelados sentimentos e vivências. Esse retrato do centro, por sua vez, cria e recria uma imagem da cidade que se assemelha à construção da Bahia propagandeada pela mídia: o Pelourinho como metonímia da Bahia em que sinos tocam nos 
ares finos dessa velha Salvador. Desse modo, ainda associado ou representativo de uma Bahia "com farofa e com dendê", uma imagem do Pelourinho, bairro antigo e um dos mais emblemáticos do centro histórico, é constituída ao longo da narrativa com marcas que indicam certa aproximação a uma representação de Bahia sagrada, mítica e sincrética. Não há um destaque ao fato de esse espaço ter sido, em certo sentido, abandonado pelo poder público e passar por constantes processos de degradação. O conto, ao descrever as vielas, gostos e cheiros sacralizados no imaginário popular, expõe uma conformação física e social do Pelourinho no final dos anos 1960 ainda marcada por uma determinada sociabilidade com trocas subjetivas mais íntimas e experiências familiares, mas já sinaliza um processo de abandono pela elite burguesa que começara a tomar novos espaços da cidade.

Historicamente, o momento representado nessa narrativa de Ribeiro é marcado por um grande crescimento populacional. Pedro de Almeida Vasconcelos (2003) denomina o período entre 1945 e 1969 como "período da pré-metropolização", quando se tem a formação de cortiços no Pelourinho. A partir das observações de Milton Santos de 1958, Vasconcelos (2003) afirma que já nessa época o centro é indicado como "área de deterioração", mas o Pelourinho ainda gozava da sociabilidade marcada pelas famílias que ali viviam e travavam suas relações sociais. No entanto, esse foi o último período em que essa região, sobretudo a parte da Cidade Alta, continuou a representar "[...] o único centro da cidade, acumulando as funções governamentais, importantes equipamentos urbanos, local de origem das principais linhas de transporte e ainda conservava um comércio dinâmico" (VASCONCELOS, 2003, p. 117). 
No conto há uma relação entre as memórias individuais e coletivas na medida em que se apresenta para o leitor uma série de imagens que integram a história da cidade, como a ladeira do pelourinho, a janela de um sobrado, a Igreja de Nossa Senhora do Rosário dos Pretos, casarões "velhos e desbotados" e o edifício Bola Verde. Revelam-se, ainda, elementos íntimos que desvendam as feições singulares do núcleo familiar, como uma antiga geladeira GE, uma mulher que arruma um quarto, um menino que brinca, livros na estante, "travessas de farofa de ovo com manteiga, arroz, carne, leite, café e deliciosas fatias de parida" (RIBEIRO, 2010, p. 22). Os tecidos da memória são responsáveis por entrelaçar a história subjetiva e urbana na formação de um único corpo narrativo.

Esse mesmo cenário, um apartamento velho no Pelourinho, que interliga a conformação urbana do antigo espaço e as memórias subjetivas de um dado personagem ou do leitor que com esse espaço tenha se relacionado - se encontra no romance $O$ chamado da noite. Nessa narrativa, um homem de meia idade, que em seu trânsito pelas ruas de Salvador constrói suas memórias, revela essa mesma centralidade urbana e as singularidades coletivas e subjetivas a partir do bairro do Pelourinho que recria:

[...] A terra do Prestes João era aquele apartamentozinho apertado no Taboão onde nas manhãs de domingo eu me reunia com minha mãe e o meu irmão mais velho, e as minhas tias, para comer feijoada e beber mirinda. E o que mais me fascinavam eram aqueles líquidos mágicos com seus nomes estranhos: mirinda, crush, grapetti, fratellivitta, enfim, que comprávamos no armazém que existe até hoje, na bola verde, em frente àquele edifício velho, caindo aos pedaços, com vista para lugar nenhum ou para uma rua suja e decadente que eu não via naquele tempo, porque tudo o que eu via em volta de mim era o mistério. [...] (RIBEIRO, 1997, p. 46).

Mais uma vez, tem-se a figura do infante a partir das lembranças e do ato de rememorar que cria e recria antigos espaços, sujeitos, objetos, situações e reelabora as 
próprias imaginações infantis. Desse modo, são retomadas antigas práticas, como a reunião familiar aos domingos, os refrigerantes que marcaram uma época e a existência dos antigos armazéns, hoje, em sua maioria, substituídos pelas grandes redes de supermercados. Percebe-se, ainda, que nessa passagem, diferente do que ocorre em "O visitante invisível", tem-se um confronto entre o cenário do passado e o da atualidade. O personagem que narra revela um panorama contemporâneo no qual uma das marcas mais expressivas é o da degradação de edifícios velhos, caindo aos pedaços, e ruas sujas e decadentes. No entanto, se isso já existia na época rememorada, era estranho ao menino que naquele espaço construíra suas fantasias.

Não se pode negar que, em Ribeiro, as representações do centro histórico de Salvador, sobretudo do bairro do Pelourinho, recriam o ar misterioso, sacralizado e até estereotipado do que se convencionou chamar de cidade da Bahia ${ }^{3}$. No entanto, nas narrativas de Ribeiro há constantes indicações do cenário de degradação vislumbrado na atualidade que ressurgem com um tom de pesar, saudosismo e nostalgia e revelam um sentimento de perda de uma Bahia que deixou de existir, ou que, em verdade, nunca existiu.

Além do centro histórico e sua antiga formação arquitetônica, as narrativas de Ribeiro revelam, a partir de uma representação do centro antigo, as práticas sociais de outro tempo. Assim, não apenas a ausência de antigos espaços inquieta os narradores e personagens de Ribeiro, mas também a saudade das práticas de sociabilidade de um outro período. Nesse

\footnotetext{
${ }^{3}$ Tal expressão, representativa do modo como ficou conhecida a cidade de Salvador até o século XX, sugere o destaque da cidade no cenário baiano e foi utilizada por muitos artistas, como Jorge Amado, Carybé, Piere Verger e Caymmi, todos eles, nos dizeres de Wan-Dall Junior $(2013$, p. 4) a partir das colocações de Drummond (2012, p. 5), responsáveis por ampliar e difundir "uma identidade da cidade de Salvador, estetizando o Centro Histórico e a 'cultura mestiça' do povo baiano.
} 
sentido, destaca-se uma passagem do romance $O$ chamado da noite (1997), no qual são valorizadas essas antigas práticas:

[...] e quem iria comprar o pão na padaria, naquela última padaria antiga que restou no bairro, a única na qual ainda vou porque somente lá alguém sabe quem sou? Lembro-me das padarias da minha infância. Eram padarias com padeiros, e padeiros tinham família e filhos e empregados e alegria e raiva e, o melhor de tudo, eles sabiam meu nome, quem era, de quem era filho e todas essas bobagens que hoje não valem mais nada, porque nas padarias modernas somos bem tratados, somos muitíssimo bem tratados, nós, os clientes, e eles nos tratam bem porque é bom para eles que sejamos bem tratados, porque somos $O$ Cliente, e para eles ganharem mais dinheiro do que o concorrente, eles têm que tratar bem o cliente, mas isso é bobagem, pois insisto em comprar o meu pão na velha padaria e creio mesmo que sou um dos últimos clientes e que em breve eles também fecharão as portas e então terei que comprar pão nessas padarias que parecem mais um shopping Center. (RIBEIRO, 1997, p. 15).

Nessa passagem, em especial, além de um retrato das antigas padarias da cidade, há uma representação de práticas de sociabilidade de outrora, em que as relações humanas apresentavam uma troca subjetiva mais íntima, e as pessoas de um mesmo bairro ou rua, por exemplo, reconheciam-se pelo nome. Trata-se, por óbvio, de uma lembrança que não pertence apenas ao narrador do texto, mas àqueles que, de alguma forma, experimentaram essa prática e, assim como o narrador, espantam-se ao se depararem com outro cenário na contemporaneidade, o que ratifica uma relação entre memórias subjetivas e coletivas a partir da representação do espaço urbano.

Ao se pensar essa escrita da memória, percebe-se que a retomada do passado no romance, atrelada a uma leitura das demais produções de Carlos Ribeiro, permite que se aponte tal elemento da narrativa como uma marca crítica e denunciativa. É possível se afirmar que a tentativa de retornar aos espaços do passado, por meio da criação ficcional, 
objetiva contrapor passado e presente, a fim de evidenciar a diminuição das funções que eram exercidas por aquele espaço central. $\mathrm{Na}$ atualidade, o centro antigo, sobretudo a região do Pelourinho, perdeu a sua posição como espaço central das atividades urbanas, cabendo às narrativas memorialísticas representar nostalgicamente seu antigo vigor, uma vez que viajar "[...] no passado, na tradição, é transformá-lo, salvando-o do esquecimento, tornando-o produtivo: ramos viçosos" (GOMES, 1994, p. 45).

Comentando a obra de Walter Benjamim, Infância em Berlim, Renato Cordeiro Gomes (1994) apresenta importantes relatos que evidenciam o modo pelo qual as imagens benjaminianas tentam reconstruir a infância por meio dos "labirintos da recordação". O mesmo ocorre nas narrativas de Carlos Ribeiro. Assim como em Infância em Berlim, abordada por Gomes (1994), o conto "O visitante invisível" e outras histórias de Ribeiro representam uma tentativa de, através do registro escrito, preservar memórias da cidade que estão diretamente atreladas às vivências da infância. Gomes (1994, p. 65) cita colocação de Bolle (1984, p. 3-5) sobre a memória e a cidade: "recuperar o passado significa: construir o sentido e o presente, tendo como arma de resistência a memória afetiva, por meio da memória topográfica". Em Ribeiro, o que se coloca é exatamente essa tentativa de se recuperar o passado por meio dos espaços que constituem os tecidos da memória urbana e dos narradores e personagens. Percebe-se, assim, que, na ficção de Carlos Ribeiro, tanto neste conto quanto em outras narrativas, faz-se constante uma tentativa de se retomar os espaços e vivências do passado. O ato de rememorar surge, sobretudo, a partir do perambular pela cidade de hoje que apresenta os resquícios de outra época. Esses resquícios, por sua vez, dizem respeito tanto às experiências singulares vividas na esfera 
familiar quanto às vivências coletivas nos ambientes culturais que se faziam marcantes nos espaços do antigo centro e o valorizam como patrimônio cultural a ser salvaguardado.

\section{REFERÊNCIAS}

BOSI, Ecléa. Memória e sociedade: lembranças de velhos. São Paulo: T.A Queiroz, 1979.

DRUMMOND, W. L. L.. Ruínas identitárias - fantasmagorias e Centro Histórico. In: III Seminário Internacional Morte e Vida dos Centros Urbanos. Salvador: Edufba, 2012.

DUARTE, Fábio. Crise das matrizes espaciais: arquitetura, cidades, geopolítica, tecnocultura. São Paulo: Perspectivas; FAPESP, 2002.

FIGUEIREDO, Eurídice. Formas e variações autobiográficas. A autoficção. In:

Mulheres ao espelho: autobiografia, ficção, autoficção. Rio de Janeiro: EdUERJ, 2013.

FONSECA, Maria Cecília Londres. O patrimônio em processo: trajetória da política federal de preservação no Brasil. 2 ed. Rio de Janeiro: Editora UFRJ: MinC - Iphan, 2005.

FREUD, Sigmund (1899). Lembranças Encobridoras. In: . Obras Completas de Sigmund Freud. Disponível em:

$<<$ http://www.ebah.com.br/content/ABAAAADdUAA/freud-primeiras-publicacoes-psicanalit icas?part=13 >> Acesso em: 10 jan. 2015.

GIOVANAZ, M. Marlise. Pedras e Emoções: os percursos do patrimônio. Em Questão (UFRGS), Rio Grande do Sul, v. 13, n. 2, p. 235-242, 2007.

GOMES, Renato Cordeiro. Todas as cidades, a cidade: literatura e experiência urbana. Rio de Janeiro: Rocco, 1994.

HALBWACHS, Maurice. A memória coletiva. São Paulo: Revista dos Tribunais. 1990.

HUYSSEN, Andreas. Seduzidos pela memória: arquitetura, monumentos, mídia. Rio de Janeiro: Aeroplano, 2000.

NORA, Pierre. Memória: da liberdade à tirania. In: MUSAS: Revista Brasileira de Museus e Museologia, n. 4, 2009. Rio de Janeiro: IBRAM, 2009. p.06-10.

RIBEIRO, Carlos. O chamado da noite. Rio de Janeiro: Sette Letras, 1997. Contos de sexta-feira e duas ou três crônicas. Salvador: Assembleia Legislativa do Estado da Bahia, 2010. 
VASCONCELOS, Pedro de Almeida. A cidade alta de Salvador: de cidade colonial a centro histórico pós-moderno. In: CARLOS, Ana Fani Alessandri; LEMOS, Amália Inês Geraiges. Dilemas Urbanos: novas abordagens sobre a cidade. São Paulo: Contexto, 2003. v. 1, p. 110-118.

WAN-DALL JUNIOR, O. A.. Ruas, ruínas e outros mistérios: sobre os processos de subjetivação da cidade de Salvador. In: XV ENANPUR - Desenvolvimento, planejamento e governança, Recife, 2013.

Artigo recebido em: 31 de maio de 2018. Artigo aprovado em: 17 de setembro de 2018. 